between deliveries by forceps and those by vacuum extraction, ${ }^{8}$ though mild neonatal jaundice was still more frequent in the vacuum extractor group. In a long term follow up comparison at the age of 4 of 101 children delivered by vacuum extraction and a matched control group of infants delivered spontaneously Bjerre and Dahlin found no differences in psychomotor development and neurological features. ${ }^{15}$

The evidence shows, then, that maternal complications are unquestionably less severe after vacuum extraction than after forceps deliveries. Vacuum extraction may be used for midpelvis extraction as an alternative to caesarean section and is preferable to forceps in occipitolateral positions, since the head often rotates spontaneously during vacuum extractor extraction. In deliveries by vacuum extraction the mother takes an active part by bearing down during extraction, and this might also contribute to her positive emotional experience of the delivery. The hazard with vacuum extraction is that since the instrument is so easy to apply it may be used uncritically to hasten delivery. If it is used when the presenting part is high in the pelvis the extraction time may become too long, which increases the risk of serious scalp abrasions, neurological complications, and neonatal infections. In outlet extractions with the fetal head in the occipitoanterior or occipitoposterior position forceps delivery seems to be as suitable as delivery by vacuum extractionbut only in the hands of a trained obstetrician.

Should the vacuum extractor substitute for the forceps in everyday obstetrics younger obstetricians would still need to be trained in handling both instruments. In certain conditions-including premature deliveries and the aftercoming head in breech presentation-and in those deliveries in which the parturient is unable to participate the forceps remains the correct instrument.

Head of Obstetric Division,

GUNNAR RYDÉN

Department of Obstetrics and Gynaecology,

University Hospital,

58185 Linköping,

Sweden

1 Malmström T. Vacuum extractor-an obstetrical instrument. Acta Obstet Gynecol Scand 1954;33(suppl 4): 1-32

2 Bird GC. Modification of Malmström's extractor. BrMed $\mathcal{f} 1969 ;$;ii:526.

3 Bird GC. The importance of flexion in vacuum extractor delivery. $\mathrm{Br} \mathcal{F}$ Obstet Gynaecol 1976;83:194-200

4 Fjällbrant B. VE Trials followed by caesarean section. Gynecologia 1964;157:161-5.

5 Chalmers JA, Prakash A. Vacuum extraction initiated during the first stage of labour. $\mathrm{Br} f \mathrm{Obstet}$ Gynaecol 1971;78:554-8.

6 Lasbrey AH, Orchard CD, Crichton D. A study of the relative merits and scope for vacuum extraction as opposed to forceps delivery. S Afr 7 Obstet Gynaecol 1964;2:1-8.

Greis JB, Bieniarz J, Scommegna A. Comparison of maternal and fetal effects of vacuum Greis $J B$, Bieniarz $J$, Scommegna A. Comparison of maternal and fetal
extraction with forceps or cesarean deliveries. Obstet Gynecol 1981;57:571-7.

8 extraction with forceps or cesarean deliveries. Obstet Gynecol 1981;57:571-7. vacuum extraction and forceps delivery. Br $\mathcal{J}$ Obstet Gynaecol 1983;90:1107-12.

Egge $K$, Lyng G, Maltau JM. Effect of instrumental delivery on the frequency and severity of gee K, Lyng G, Maltau JM. Effect of instrumental delivery on the frequency
retinal hemorrhages in the newborn. Acta Obstet Gynecol Scand 1981;60:153-5.

10 Ehlers N, Jensen IBK, Hansen KB. Retinal haemorrhages in the newborn. Comparison of delivery by forceps and vacuum extractor. Acta Ophthalmol 1974;52:73-82.

1 Plauché WC. Fetal cranial injuries related to delivery with the Malmström vacuum extractor. Obstet Gynecol 1979;53:750-7.

12 Leijon I. Neurology and behaviour of newborn infants delivered by vacuum extraction on maternal indication. Acta Paediatr Scand 1980;69:625-31.

3 Fall O, Finnström K, Finnström O, Leijon I, Rydén G. Forceps or vacuum extraction. A comparison of effects on the newborn infant. Acta Obstet Gynecol Scand (in press).

4 Jeannin $P$, Afschrift $M$, Voet $D$, et al. Cranial ultrasound after forceful mid-pelvis vacuum extraction at term. $\mathcal{T}$ Perinat Med 1984:12:319-23.

Bierre I, Dahlin K. The long-term development of children delivered by vacuum extraction. Dev Med Child Neurol 1974;16:378-81.

\section{Doctors and torture}

The political conditions which lead to doctors participating in the abuse of human rights may be seen all too clearly under the oppressive regimes of some South American states. The Collegio Medico de Chile (Chilean Medical Association) has recently suspended two doctors for their involvement in torture, and late last year it held an international meeting on human rights attended by representatives of the medical associations of other countries. This week will also see the launching in Britain of the Medical Foundation for the Care of Victims of Torture ( $p$ 142).

At the time of the overthrow in 1973 of the government of Dr Allende, a former president of the Collegio, human rights were not mentioned in the code of medical ethics-because no one thought it necessary. There may have been serious economic and social problems, but democratic rights were respected and the rule of law was enforced.

The right wing take over in 1973 changed all that, and the concept of "national security" was born. The paramount need to eliminate "the basic cancer of marxism" was held to justify suspension of constitutional freedoms, with alternate phases of "siege" and the marginally less oppressive phases of "emergency." Not only those suspected of marxist tendencies but also their relatives, friends, and contacts have been taken from their homes and tortured to obtain information or banished to remote parts of the country. Children are not exempt: in 1984 the secret police arrested at least 455 children under 16, of whom 16 died and many more have permanent disabilities from gunshot wounds and head injuries. The rehabilitation of victims of torture, especially of children, is one of the problems confronting the Collegio.
Another problem is rape, which is rare in Chile except in assaults by the civil and military police. Doctors' daughters have been included among their victims. Fear of reprisals, shame, and the fact that there are few facilities for treating the immediate aftermath of rape had led to many cases going unreported; in these circumstances both infection and pregnancy have occurred. Abortion is illegal.

The high sounding resolutions against brutal and inhuman treatment that come from the United Nations and other international organisations are in stark contrast to their ineffectiveness in Chile. Amnesty International claims that torture is occurring in more than half the countries of the world. Electrical apparatus used for torture in Chile is said to have been manufactured in England and Japan. How sincere are the "protesting" governments? The many non-governmental organisations are more effective, but their activities are fragmented and incoordinated.

The World Medical Association (notwithstanding its declaration on the issue) has been so ineffective that the Uruguayan Medical Association has decided to join the long list of those who have left that discredited body. It was noticeable that neither the WMA nor its most influential member, the American Medical Association, was present at the conference, although the World Psychiatric Association and the American Institute for the Advancement of Science were strongly represented.

The BMA's working party on torture set up as a result of the resolution passed by the annual representative meeting in 1984 will soon have finished its task, and its report can be expected to refer to what has now become known as the 
"medicalisation" of torture. The lesson to be learnt from the experience in Chile is the relative ease with which the isolated doctor can progress from simply failing to note the signs of violence on a detainee to his actual presence at an interrogation-unless he is strongly supported by the collective views of his colleagues. A national medical association which provides such support, at great personal risk to its officers, deserves the support of all the medical associations of the free world. The secret police visited the conference one night and took away papers. The next day 16 plainclothed policemen raided the Human Rights office in Santiago, assaulted the staff, and took away documents and typewriters. Many doctors have been tortured or banished, and some of them have been refused permission to return to Chile as a result of their political views.

The international reaction has been to isolate Chile. Only two inquiries have been received from British medical students about electives in Chile, and there has been no exchange of junior doctors. Ostracism only plays into the hands of the oppressive regime in Chile by concealing from the rest of the world what is going on. The courageous stand being taken by the Collegio in enforcing principles of medical ethics deserves all the international support it can get.

Secretary,

J D J HAVARD

British Medical Association
Two recent surveys of the use of ultrasound in obstetrics in Britain have shown that radiographers carry out most of the examinations. ${ }^{1}$ Most of these radiographers hold a certificate of special training in ultrasound (the Diploma of Medical Ultrasound of the College of Radiographers). Nevertheless, when they talk to the patients to explain and reassure they are contravening the guidance given by the disciplinary committee of the Radiographers Board in consultation with the Council for the Professions Supplementary to Medicine.

These guidelines put the radiographer in a difficult position; and a minority are sufficiently worried to feel unable to explain their findings to patients, particularly if they suspect an abnormality. Witcombe and Radford have shown that in some institutions there is no medical cover available for radiographers, and discussions at the annual scientific meeting of the British Medical Ultrasound Society in 1983 showed that most radiographers who did have medical cover believed that they knew more about the subject than did the supervising doctor. In many departments the written reports on ultrasound examinations performed by radiographers are signed or countersigned by doctors who neither saw the examination nor could make any comment on its technical adequacy or findings. Clearly, then, the provision of obstetric ultrasound services has outstripped the ability of the medical profession either to perform or to supervise the service, and unacceptable burdens are being placed on some radiographers.

The College of Radiographers is to be congratulated on at least making a start seven years ago to ensure adequate training and certification for those of its members who perform ultrasound examinations by introducing its diploma in medical ultrasound. The current diploma is not, however, a certificate of competence at performing or interpreting ultrasound scans, and the syllabus does not include training in handling and communicating with patients and their relatives. The deficiencies in ultrasound services identified by the Royal College of Obstetricians and Gynaecologists ${ }^{1}$ and by Witcombe and Radford ( $p$ 113) have been supported from the consumer's viewpoint by a recent survey of its members conducted by the National Childbirth Trust. ${ }^{2}$ This report highlighted the importance to the patient of communication with the operator and the profoundly adverse psychological effects when such rapport was missing. Its authors seemed to be unaware that a radiographer is contra- vening official policy if, in the interest of the patient she is examining, she chooses to communicate her findings.

These reports have identified three separate problems: the inadequate status and professional responsibility for radiographers performing obstetric ultrasound examinations; the deficiencies in the training and testing of ultrasonographers; and the poor quality and quantity of medical supervision of obstetric ultrasound services in many hospitals. What are the realistic solutions?

The emphasis must be on realism. Radiographers perform most of the scans because doctors either do not have the time and inclination to scan or consider ultrasound an appropriate task for radiographers. Whichever is true we may assume that the pressure of work on obstetricians and radiologists will ensure that the medical contribution is unlikely to increase. The priority must, therefore, be an improvement in training and testing of radiographers for this work. Improvement in their status and redefinition of their professional obligations would follow. These ends might be achieved by introducing a special diploma in obstetric ultrasound, as recommended by the college report, which suggests that the responsibility should be shared by the Royal College of Obstetricians and Gynaecologists and the Royal College of Radiologists. ${ }^{1}$ Until now, however, neither college has offered diplomas to non-medical health professionals, and there seems no precedent for such an action. Possibly any new diploma should be awarded by a body such as the College of Radiographers, or by technical colleges and universities, or by the Council for National Academic Awards. Whoever establishes the diploma, the examination will need to include a practical test of the candidate's ability to perform an examination and interpret the results. Holders of this higher diploma might then be given specific licence to interpret their findings and to communicate these to the patients. Some doctors may not agree with such a proposal, but I have no doubt that many radiographers currently practising obstetric ultrasound already have the necessary skills and are assuming such a status without certification or the consent of their employers.

A solution more acceptable to the medical profession might be a special course of training and certification for interested radiologists and obstetricians. The Royal College of Obstetricians and Gynaecologists' report recommends that the medical supervisor of an ultrasound service should regularly perform at least one full ultrasound session a week 